\title{
Prevalence of vulvovaginal candidiasis among pregnant women in the Ho municipality, Ghana: species identification and antifungal susceptibility of Candida isolates
}

Sayanika Devi Waikhom ${ }^{1 *}$, Innocent Afeke², Grace Sefakor Kwawu², Hintermann Kobina Mbroh³, George Yiadom Osei ${ }^{2}$, Bengyella Louis ${ }^{1}$, John Gameli Deku², Emmanuel Senyo Kasu ${ }^{4,5}$, Prosper Mensah ${ }^{6}$, Charles Yao Agede ${ }^{6}$, Cornelius Dodoo ${ }^{7}$, Emmanuel Akomanin Asiamah' ${ }^{2}$, John Tampuori ${ }^{8}$, John Korbuvi ${ }^{9}$ and Japheth Awuletey Opintan ${ }^{10}$

\begin{abstract}
Background: Candida is the leading cause of vaginitis, and $75 \%$ of women have at least one episode of infection in their lives, with pregnancy being a predisposing factor. If left untreated, vulvovaginal candidiasis (WC) can lead to chorioamnionitis with subsequent abortion, prematurity and congenital infection of the neonate. We aimed to determine the prevalence of WC, identify the recent and most frequently occurring species of Candida in pregnant women, and determine the most effective antifungal drug of choice for treatment.

Method: A prospective cross-sectional study in which 176 high vaginal swab samples of consented pregnant women visiting the antenatal clinic from February 2018 to April 2018 were subjected to direct gram smear and culture for Candida isolation. Candida isolates were identified using a germ tube test and HiCrome Candida differential agar. Candida isolates were then subjected to a disk diffusion method using fluconazole $(25 \mu \mathrm{g})$, nystatin (100 units), and voriconazole (1 $\mu \mathrm{g}$ ) on Mueller-Hinton agar supplemented with 2\% (w/v) glucose and $0.5 \mu \mathrm{g} / \mathrm{ml}$ methylene blue dye to determine the susceptibility pattern as per the guidelines of the Clinical Laboratory Standard Institute (CLSI). Chi-square analysis was used to ascertain the significant association of participants' sociodemographics and clinical presentations to WC. A univariate logistic regression model was used to identify potential risk factors of WC.

\footnotetext{
* Correspondence: swaikhom@uhas.edu.gh

1 Department of Biomedical Sciences, School of Basic and Biomedical Sciences, University of Health and Allied Sciences, PMB 31 Ho, Ghana

Full list of author information is available at the end of the article
}

(c) The Author(s). 2020 Open Access This article is licensed under a Creative Commons Attribution 4.0 International License, which permits use, sharing, adaptation, distribution and reproduction in any medium or format, as long as you give appropriate credit to the original author(s) and the source, provide a link to the Creative Commons licence, and indicate if changes were made. The images or other third party material in this article are included in the article's Creative Commons licence, unless indicated otherwise in a credit line to the material. If material is not included in the article's Creative Commons licence and your intended use is not permitted by statutory regulation or exceeds the permitted use, you will need to obtain permission directly from the copyright holder. To view a copy of this licence, visit http://creativecommons.org/licenses/by/4.0/. The Creative Commons Public Domain Dedication waiver (http://creativecommons.org/publicdomain/zero/1.0/) applies to the data made available in this article, unless otherwise stated in a credit line to the data. 
(Continued from previous page)

Results: The prevalence of WC among our study participants was 30.7\%. Non-albicans Candida (NAC) and Candida albicans had a prevalence of 74.1 and 25.9\%, respectively. Candida glabrata was the most common species, followed by Candida albicans, Candida krusei, and Candida parapsilosis. 50.0, 18.5 and 3.7\% of Candida species were susceptible to voriconazole, fluconazole and nystatin, respectively, whereas 37.0, 48.1 and 9.3\% of Candida species were resistant to voriconazole, fluconazole and nystatin, respectively. The majority of isolates were susceptible dose dependent to all three antifungal agents, with voriconazole being the most efficacious antifungal agent. There was no significant association between participants' socio-demographic information and clinical presentations to WC.

Conclusion: The prevalence of WC was high in the study area. C. glabrata was found to be the most common cause of WC among the pregnant women attending antenatal clinics, in the Ho Municipality region of Ghana. The majority of the Candida isolates were susceptible and resistant to voriconazole and fluconazole, respectively.

Keywords: Vulvovaginal candidiasis, Symptomatic vulvovaginal candidiasis, Asymptomatic vulvovaginal candidiasis, Germ tube test, HiCrome Candida differential agar, Fluconazole, Voriconazole, Nystatin, Non-albicans Candida,

Candida albicans

\section{Background}

Candida is the leading cause of vaginitis, and $75 \%$ of women have at least one episode in their lifetimes $[1,2]$. Pregnancy is a predisposing factor for vulvovaginal candidiasis (VVC) [3-5]. During pregnancy, there is an increase in progesterone and oestrogen levels, especially in the last trimester [6-8]. Progesterone has an inhibitory effect on the anti-Candida activity of neutrophils [6]. On the other hand, oestrogen reduces the ability of vaginal epithelial cells to inhibit the growth of Candida albicans on them [9]. However, about $75 \%$ of women generally harbour this fungus without it causing harm to them [10-12]. During normal pregnancy, candidiasis is frequently encountered without significant risk for the foetus. Nevertheless, pregnancy may be negatively affected by VVC. If untreated, vaginal candidiasis can lead to chorioamnionitis with subsequent abortion and prematurity in pregnant women, congenital infection of the neonate and pelvic inflammatory disease (PID) resulting in infertility in non-pregnant women [12]. VVC could be a risk factor for candidemia in preterm neonates during normal pregnancy. Amongst the Candida species isolated from vaginal specimens, $C$. albicans is the most predominant, followed by other non-albicans Candida (NAC) such as C. glabrata, C. tropicalis, C. dubliniensis and $C$. krusei [13-15]. With the increase in frequency of non-albicans Candida being isolated from clinical specimens, recent studies indicated that non-albicans Candida are now considered pathogens [16, 17]. As a result, compared to Candida albicans, NAC are developing resistance to most antifungals used as therapy to treat VVC $[16,17]$. This is widely attributed to the use of over the counter (OTC) drugs and empiric regimes to treat these infections, since speciation and antifungal susceptibility testing of Candida isolates are not done routinely for clinical purposes $[18,19]$ in Ghana. Most frequently, azole-based drugs are the drug of choice for treating Candida infections [20]. In Ghana, there is paucity of data regarding the prevalence of VVC, its distribution and the in vitro antifungal susceptibility pattern of Candida isolates from vaginal swabs of pregnant women. With the increasing shift in population of Candida species, from C. albicans to NAC, and the rapid development of resistance to drugs being administered, it is imperative to study the antifungal susceptibility of Candida species among pregnant women in the Ho Municipality. Early diagnosis and appropriate treatment may improve the pregnant women's and neonates' clinical conditions [21]. Identification of Candida species in human infections has increased, and may partly be due to improvements in diagnostic methods such as the use of chromogenic media, which has the ability to differentiate pathogenic Candida isolates into their individual species [22]. Chromogenic agar is rapid, simple and cost effective compared to conventional methods, which are slow, technically demanding and expensive [23, 24].

This study was designed to ascertain the prevalence of VVC, identify the recent and most occurring species of Candida associated with VVC in pregnant women and determine the most effective antifungal drug for treatment.

\section{Methods}

\section{Study site and study design}

This prospective cross-sectional study enrolled 176 pregnant women with complete data who visited the antenatal clinics (ANC) at the Ho Teaching Hospital (HTH) and the Ho Municipal Hospital (HMH) from February 2018 to April 2018. HTH is the major referral center in the Volta Region. These health facilities are situated in Ho, the capital city of the Volta Region. At average, 20 and 15 pregnant women are seen at the ANC on a daily 
basis at the HTH and $\mathrm{HMH}$, respectively. Processing of samples was done at the Microbiology unit of the $\mathrm{HTH}$ laboratory.

\section{Study population, participant's selection and recruitment} Pregnant women in any trimester who visited the ANC were interviewed one-on-one and those that gave consent to be part of the study were enrolled. Pregnant women who had any pregnancy related complications (diabetes, bleeding per vagina, hypertension) or were on either antifungal agents/antibiotics were excluded in the study. Pregnant women were enrolled once to avoid repetition.

\section{Study procedure}

Information regarding participants' socio-demographics (age, educational level, marital status, religion, trimester in pregnancy) and clinical presentations (burning sensation, discharge and irritation) were extracted from participants' ANC books. Information that were not readily available in the ANC books were collected using semistructured questionnaire administered to participants of the study. Patients were assigned study identification numbers (IDs) which were used throughout the study. The IDs were generated by using the initials of the hospital where participants were enrolled and a chronological number according to how the patients were recruited.

After detailed explanation of the sampling procedure to the participants, two high vaginal swabs (HVS) were obtained by a Gynecologist/trained midwife from each participant using sterile swab sticks. The samples were labelled using generated IDs of study participants. Each participant was made to lie in a lithotomic position where the vaginal walls were examined for white patches. Using a speculum, the labia of the vagina was opened, and a sterile swab stick was inserted into the vagina to the posterior fornix where the swab stick was gently rotated around to soak fluid unto the sterile cotton bud. The procedure was repeated to obtain two HVS. Samples obtained were transported in Amies transport medium to the laboratory within $1 \mathrm{~h}$ for bacteriological analysis. Based on the combination of the clinical presentations, Gram and culture outcome, participants were categorized into three groups; symptomatic, asymptomatic and negative VVC. Symptomatic vulvovaginal candidiasis was defined as the presence of clinical presentations (burning sensation, discharge, and irritation) and the presence of yeast-liked cells in direct Gram smear with positive culture. Asymptomatic VVC (colonization) was defined as the absence of clinical presentations (burning sensation, discharge, and irritation) but the presence of yeast-liked cells in direct Gram smear with positive or negative culture. A negative case was defined as the absence of clinical presentations and the absence of yeast-like cells in direct Gram smear with negative culture.

\section{Laboratory test processes}

HVS samples were processed at the Microbiology laboratory of the Ho Teaching Hospital within $1 \mathrm{~h}$ of collection. One swab was used for culture and the other for direct Gram smear for Gram positive oval-shaped organisms with buds and/or pseudohyphae/hyphae (Fig. 1).

Swabs were inoculated on Sabouraud Dextrose agar (SDA) (TPC, India) plates and incubated aerobically at $37^{\circ} \mathrm{C}$, for $24 \mathrm{~h}$. Plates with no growth after $24 \mathrm{~h}$ were reincubated for another 24h $[25,26]$ (Fig. 2). Colonies on SDA plates were subjected to colony identification and Gram staining for yeast-like cells. All isolates (54) were stored in Brain Heart Infusion (BHI) (Oxoid Ltd., England) with $15 \%$ glycerol at $-20^{\circ} \mathrm{C}$ for further research.

Yeast-like cells were speciated by subjecting them to germ tube test. Small portions of isolated colonies of the yeasts were suspended in test tubes containing $0.5 \mathrm{ml}$ human serum. The test tubes were incubated at $35^{\circ} \mathrm{C}$ for $4 \mathrm{~h}$. A drop of the well-mixed incubated suspensions was placed on clean grease-free microscope slides with a cover slip and observed using $\times 40$ objective magnification. Filamentous extension from yeast cell with no constriction at the neck was considered as germ tube positive. Isolates with no extensions or extensions with constrictions at the neck were considered germ tube negative [27] (Fig. 3).

Isolates were sub-cultured on HiCrome Candida differential agar (HiMedia, India) and incubated aerobically

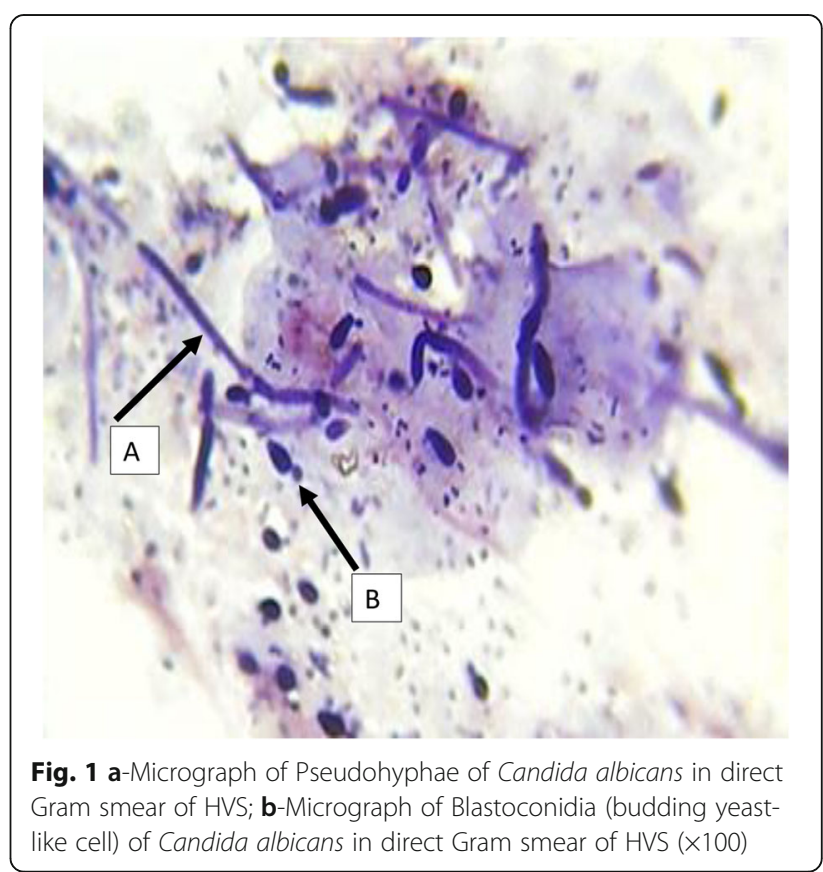




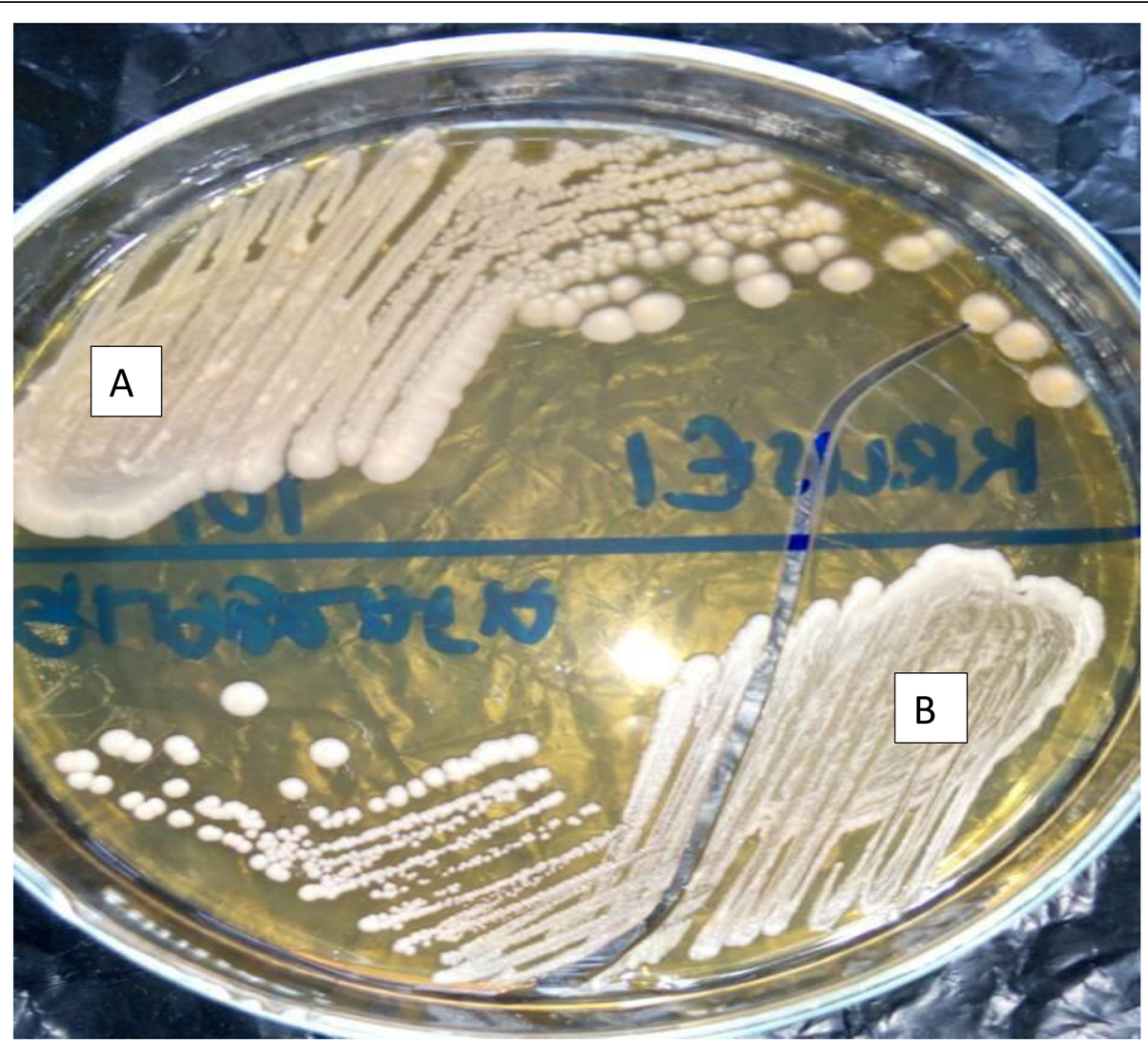

Fig. 2 a-Photograph of Candida krusei (cream, dry, dull, convex colonies) on Sabouraud Dextrose Agar; b-Photograph of Candida albicans (pale cream, smooth, glistening, convex colonies) on Sabouraud Dextrose Agar after $48 \mathrm{~h}$ of aerobic incubation at $37^{\circ} \mathrm{C}$

for $48 \mathrm{~h}$ [28]. Colonies on HiCrome Candida differential agar were identified by colour, appearance and shape (Table 1; Fig. 4).

Antifungal susceptibility testing was performed on Mueller-Hinton $(\mathrm{MH})$ agar (Oxoid Ltd., England) supplemented with $2 \%$ glucose and $0.5 \mu \mathrm{g} / \mathrm{ml}$ methylene blue by disk diffusion method for nystatin $(100 \mu \mathrm{g})$, fluconazole $(25 \mu \mathrm{g})$ and voriconazole $(1 \mu \mathrm{g})$ disks (Oxoid Ltd., England) [31, 32]. Using a sterile inoculating loop, an inoculum was prepared using distinct colonies of Candida isolates from the SDA plates which were transferred into a $5 \mathrm{ml}$ test tube containing $0.85 \%$ sterile saline solution, and emulsified to form a suspension of turbidity equivalent to 0.5 McFarland standard as compared to a 0.5 McF PhoenixSpec Calibrator (Becton, Dickinson and Company, USA). The lawn of the media was seeded in three dimensions using sterile swabs dipped in prepared inoculum. Antifungal disks were then placed aseptically on the lawn and incubated at $37^{\circ} \mathrm{C}$ for $24 \mathrm{~h}$. Plates that did not register growth were re-incubated for extra 24h [32] (Fig. 5). Zone diameters of antifungal disks were read using measuring ruler. For azoles (fluconazole, voriconazole), zones were read up to colonies of normal size; and zones of growth of partially inhibited colonies whose sizes were smaller nearer the disk than at the edge of the real zone which were not seen was considered as resistant mutants. For nystatin, clear zones with no visible growth were read. If colonies were seen inside the zone, they were considered resistant mutants [32] (Table 2). Quality control was ensured using Candida albicans ATCC 44374. Fifty percent of all setups were randomly selected and were re-examined by two other readers to ensure quality.

\section{Sample size estimation}

A sample size of 255 was obtained per calculation based on a previous data which showed that $21 \%$ of VVC is prevalent among pregnant women in Ghana [13] and a $95 \%$ confidence level with a 5\% allowable error.

\section{Data collection, management and analysis}

Both clinical and laboratory data were extracted and recorded manually into an MS-office Excel software Version 1908 (Microsoft Corporation Copyright 2016). Data was later analyzed using Statistical Package for the Social Sciences Version 22 (SPSS, SPSS Inc., Chicago, IL, USA). Categorical data variables were statistically described in the form of frequencies and percentages while 


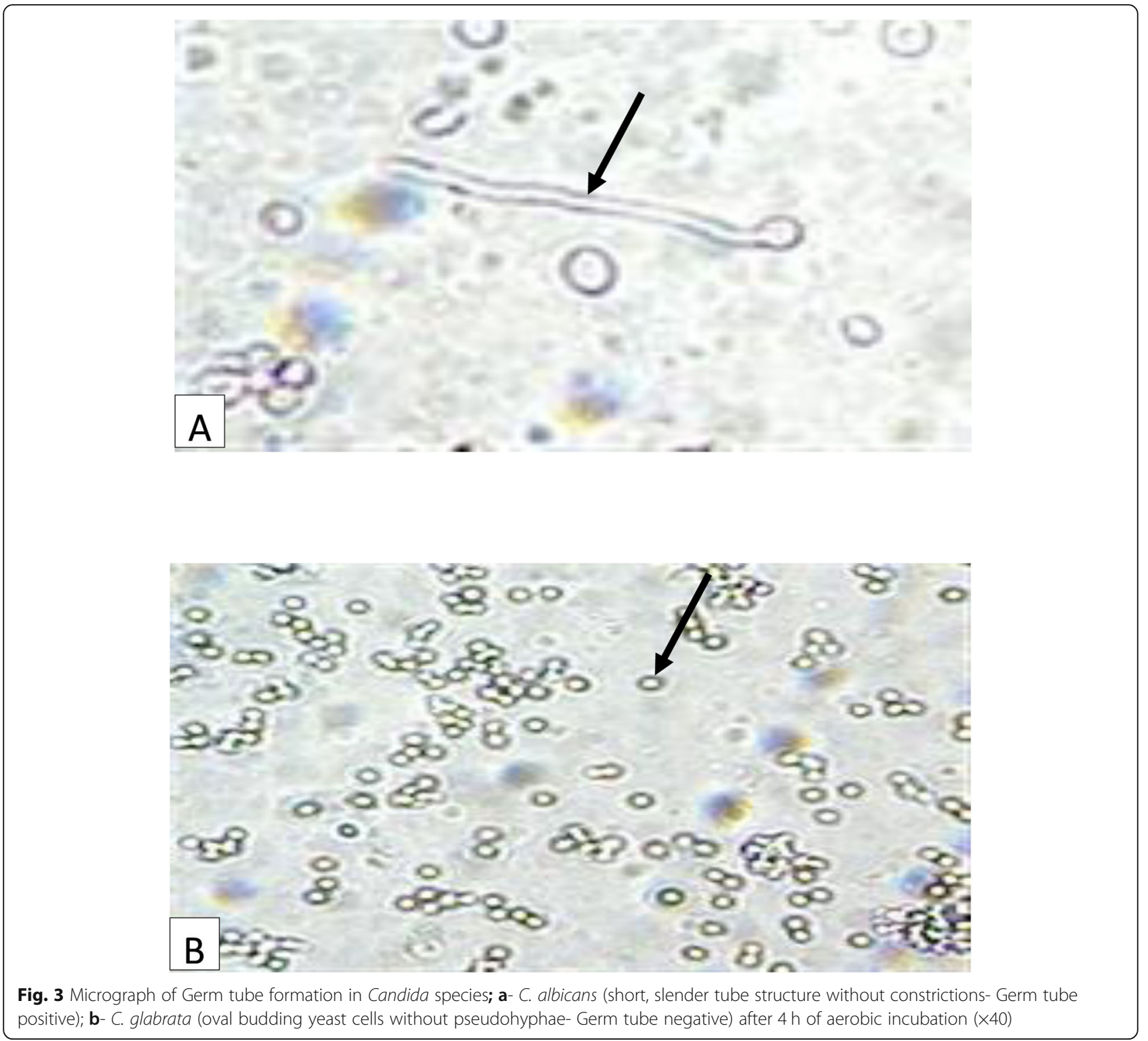

continuous data variables were summarized as mean (Standard Deviation). The association between categorical variables were done using chi-square test. $P$-value was considered significant if less than 0.05 . Univariate logistic regression model was used to identify potential

Table 1 Differentiation of Candida with HiCrome Candida Differential Agar [29, 30]

\begin{tabular}{ll}
\hline Species & Description on HiCrome Candida Differential Agar \\
\hline C. glabrata & Cream, glistening, convex, smooth \\
C. krusei & Purple, fuzzy, dull, flat, irregular \\
C. parapsilosis & Cream to pale pink, glistening, smooth, slightly raised \\
C. albicans & Light green, glistening, smooth, convex \\
\hline
\end{tabular}

risk factors of VVC. The association between VVC and clinical presentations of study participants was determined using chi-square test.

\section{Results}

Characteristics of study participants

A total of 272 participants were interviewed, but only 176 of them were eligible and consented to be part of the study. The remaining 96 pregnant women were either not eligible or verbally declined to be part of the study (Fig. 6).

Complete socio-demographic data, clinical presentations and vaginal swabs were taken from all 176 consenting participants. Participants' mean age was 29 years, with a range of $15-42$ years. Most $(59.7 \%)$ of the 


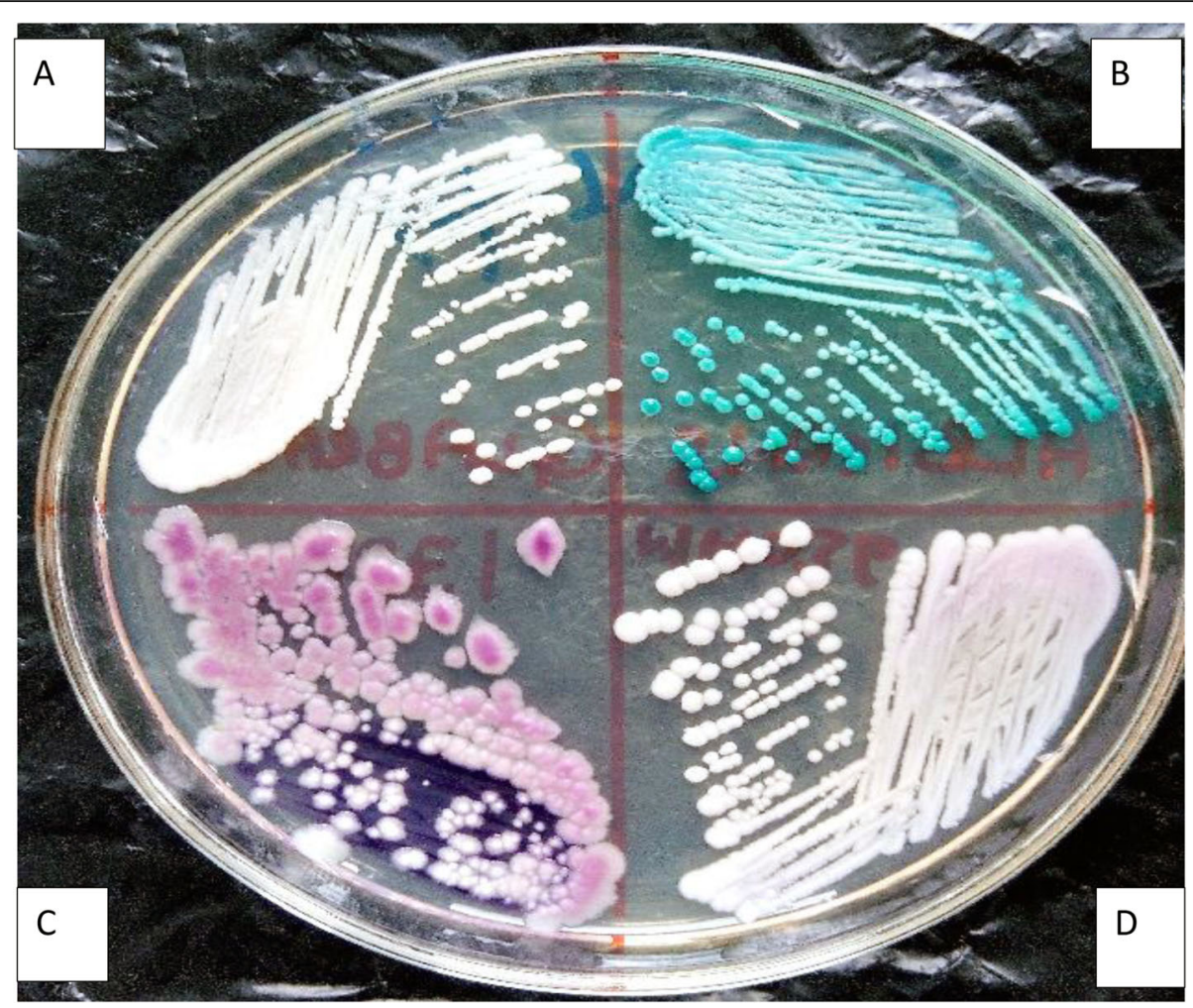

Fig. 4 Photograph of Candida species as seen on HiCrome agar a: Cream coloured, glistening, smooth, convex colonies of C. glabrata on HiCrome Candida Differential agar b: Light green coloured, glistening, smooth, convex colonies of C. albicans on Candida Differential agar C: Purple coloured, fuzzy, dull, flat, irregular colonies of C. krusei on HiCrome Candida Differential agar D: Cream to pale pink coloured, glistening, smooth, convex colonies of C. parapsilosis on HiCrome Candida Differential agar after $48 \mathrm{~h}$ of aerobic incubation at $37^{\circ} \mathrm{C}$

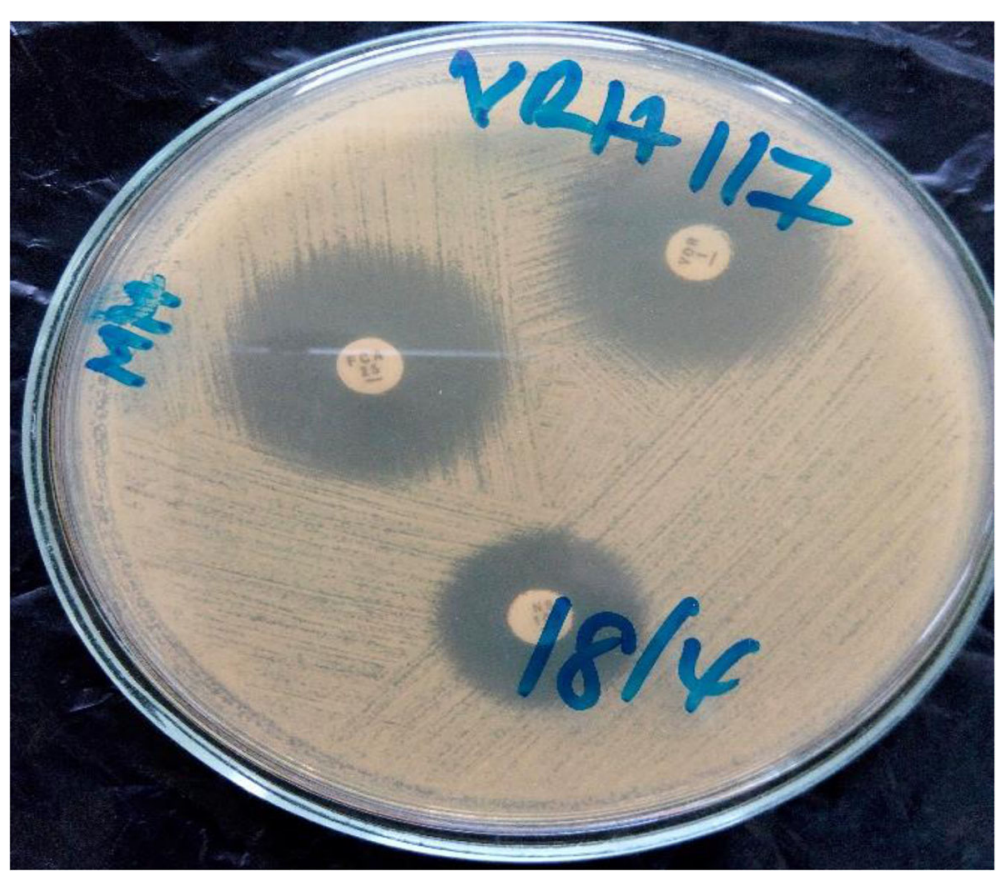

Fig. 5 Photograph of Antifungal susceptibility testing of Fluconazole $(25 \mu \mathrm{g})$, Nystatin (100 units), and Voriconazole $(1 \mu \mathrm{g})$ showing zone of inhibition on Muellar Hinton agar supplemented with $2 \%$ glucose and $0.5 \mu \mathrm{l}$ of methylene blue after $24 \mathrm{~h}$ of aerobic incubation at $37^{\circ} \mathrm{C}$ 
Table 2 Zone diameter Interpretive Standards [31, 33]

\begin{tabular}{llll}
\hline Antifungal agents & \multicolumn{2}{l}{ Zone diameter in $\mathrm{mm}$} & \\
\cline { 2 - 4 } & Resistant $(\mathrm{mm})$ & Susceptible Dose Dependent $(\mathrm{mm})$ & Susceptible $(\mathrm{mm})$ \\
\hline Fluconazole $(25 \mu \mathrm{g})$ & $\leq 14$ & $15-18$ & $\geq 19$ \\
Voriconazole $(1 \mu \mathrm{g})$ & $\leq 13$ & $14-16$ & $\geq 17$ \\
Nystatin $(100$ units) & $\leq 16$ & $17-24$ & $\geq 25$ \\
\hline
\end{tabular}

participants were in their third trimester. The majority, $73.9 \%$ were married, with $51.7 \%$ having acquired basic education. Only $2.8 \%$ had no formal education. A large majority (96.6\%) were Christians (Table 3).

Out of the 176 pregnant women, $4.5 \%$ had all three clinical presentations, with one of them diagnosed as having VVC. Approximately, 33.5\%, had discharge; the majority of these, $33.3 \%$, were VVC-confirmed participants. There was no significant association between symptoms and VVC in general, except between burning sensation and irritation (Table 4).

Among the 54 VVC-confirmed study participants, the highest frequency of Candida isolates was recorded in the age range of 20 to 29 years, with the lowest frequency in the range of 40 to 49 years. Over half, or $53.7 \%$, had basic education. A majority, or $66.7 \%$, of the VVC participants were married, with the lowest frequencies recorded in co-habiting participants. There was no statistically significant association between participants' socio-demographics and the frequency of VVC $(P>0.05)$ (Table 5).

\section{Prevalence of VVC}

The prevalence of VVC among our study participants was $30.7 \%$. Participants in their third trimester contributed to $57.4 \%$ of the VVC prevalence. Statistically, there was no significant association between symptoms and trimester of pregnancy (Table 6). Out of the $54 \mathrm{VVC}$ confirmed participants, $81.5 \%$ had symptomatic VVC, while $18.5 \%$ were colonized (asymptomatic). C. glabrata formed $57.4 \%$ of all Candida isolates among both colonized and symptomatic VVC participants, followed by $C$. albicans, with $25.9 \%$ prevalence (Table 3 ).

\section{Species identification}

Germ tube tests and cultures on HiCrome Candida differential agar were employed in the identification of Candida. Using HiCrome agar, 74.1\% NAC and 25.9\%

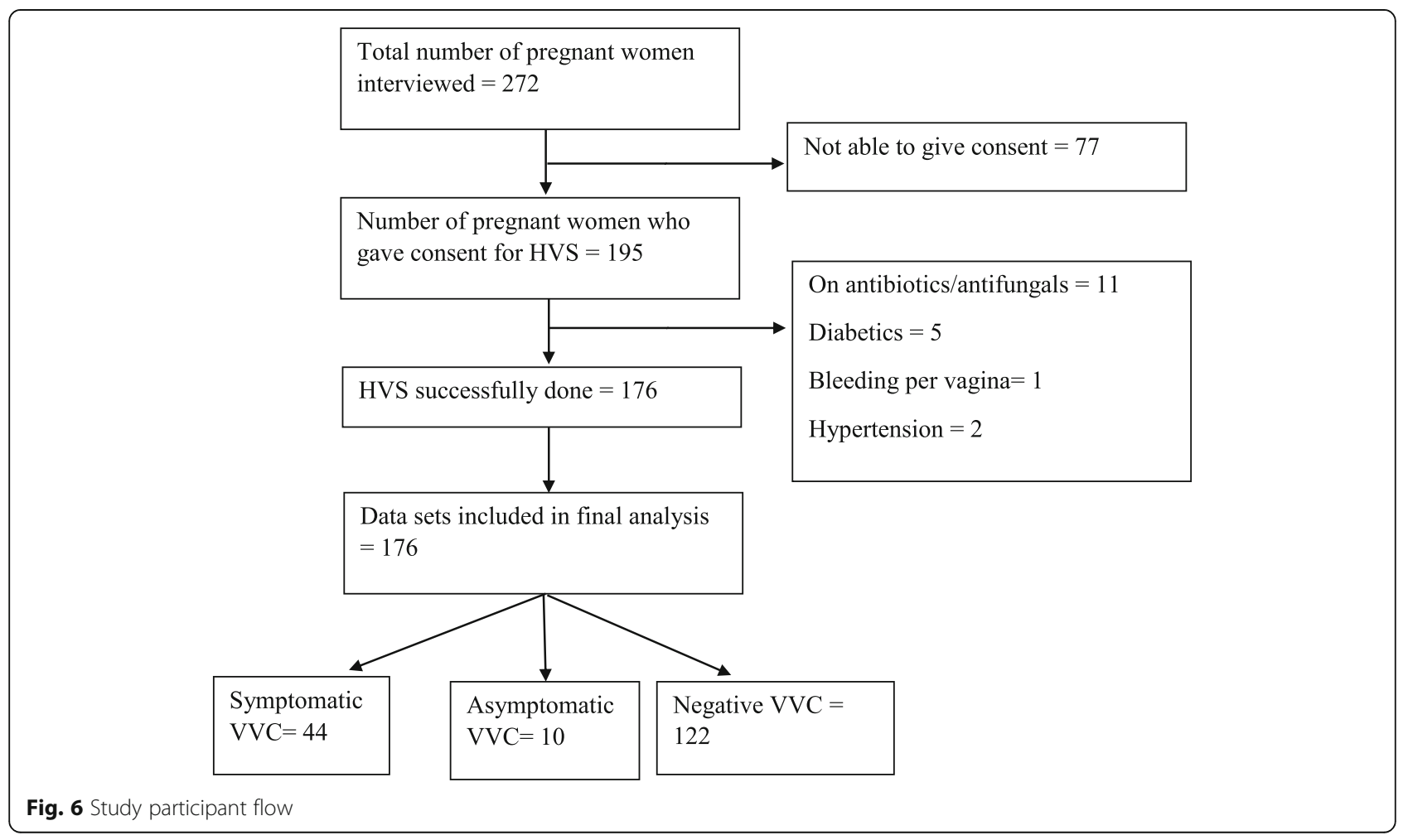


Table 3 General demographic information of study participants $(N=176)$

\begin{tabular}{|c|c|c|}
\hline Parameter & Frequency & Percentage (\%) \\
\hline Total respondents & 176 & 100 \\
\hline Age (in years) & $29(6)$ & \\
\hline
\end{tabular}

Age group (in years)

$$
<20
$$

20-29

30-39

40-49

Educational Status

None
Basic
Secondary
Tertiary

Marital Status

Single

Co-habiting

Married

Religion

Muslim

Christian

Trimester in pregnancy

$\begin{array}{ll}\text { First } & 28 \\ \text { Second } & 43 \\ \text { Third } & 105\end{array}$

Candida Infection

Negative 122

Positive (WC) 54

> symptomatic WC 44

- C. albicans 12

- C. parapsilosis 1

- C. glabrata 25

- C. krusei 6

> Asymptomatic WC 10

- C. albicans 2

- C. parapsilosis 2

- C. glabrata 6

- C. krusei

Data is presented as frequency and percentage

Mean age \pm Standard Deviation

VVC Vulvovaginal Candidiasis

C. albicans were identified. C. glabrata was the commonest isolated species, with a frequency of $57.4 \%$. About $75.9 \%$ of the Candida species were germ tube negative, while $24.1 \%$ were germ tube positive. $85.7 \%$ C. albicans were germ tube positive, while $96.8 \%$ of C. glabrata were germ tube negative.

\section{Antifungal susceptibility outcome}

The highest overall resistance rate of Candida species was seen against fluconazole (48.1\%), followed by voriconazole $(37.0 \%)$ and nystatin (9.3\%). On the other hand, Candida spp. were found to be highly susceptible to voriconazole $(50.0 \%)$, followed by fluconazole (18.5\%) and nystatin (3.7\%). Most of the Candida spp. were susceptible dose dependent (SDD) against nystatin (87.0\%) (Fig. 7).

About $21 \%$ of C. albicans were susceptible and 50.0\% were resistant to fluconazole. Among the NAC species, $17.5 \%$ were susceptible and $47.5 \%$ were resistant to fluconazole. When treated with nystatin, $5.0 \%$ of NAC were susceptible and $12.5 \%$ were resistant, respectively. The majority of the NAC spp. (82.5\%) were SDD against nystatin. When treated with voriconazole, 42.9 and 50.0\% of $C$. albicans were susceptible and resistant, respectively, while $52.5 \%$ of the NAC species were susceptible and $32.5 \%$ were resistant to voriconazole. Among the NAC species, 19.4, 41.9 and $38.7 \%$ of C. glabrata were susceptible, SDD and resistant to fluconazole, respectively. None of C. glabrata were susceptible to nystatin, but $87.1 \%$ were SDD, with a few $(12.9 \%)$ being resistant. Most of C. glabrata (54.8\%) were susceptible to voriconazole, while $35.5 \%$ were resistant. All C. krusei were resistant to fluconazole (Table 7).

\section{Discussion}

This cross-sectional study was conducted to ascertain the prevalence of VVC, species identification and antifungal susceptibility of Candida isolates from pregnant women at an antenatal clinic. This study is important, since diagnosis and treatment of VVC in Ghana are mostly done on the basis of clinical presentations, without any laboratory diagnosis. The mean age of the study participants was 29 years, which correlates with the mean age of 31.5 years reported by Sasikala et al. [15]. On the contrary, a higher mean age of 37.3 years was reported by Amar et al. [34]. Most of our participants were within the range of 20-29 years, followed by 30-39 years, which correlates with the previous reports [34, 35]. However, this was not statistically significant ( $p=$ $0.653 ; p>0.05)$. The highest frequency of VVC in pregnant women in the same age groups was reported by Rati et al. [36] and Damen et al. [17]. Although the association was not statistically significant, the majority of the VVC confirmed participants were in their third trimester [6-8] and had only basic education. Low educational background may correlate with poor personal hygiene and/or low economic status, which may, in turn, make the pregnant women prone to VVC [26]. Most of 
Table 4 Distribution of signs and symptoms among study participants

\begin{tabular}{|c|c|c|c|c|}
\hline SYMPTOMS & TOTAL & Positive & OR $(95 \% \mathrm{Cl})$ & $P$-value \\
\hline All Symptoms & $8(4.5)$ & $1(1.9)$ & $0.50(0.06-4.56)$ & 0.539 \\
\hline Burning Sensation \& Discharge only & $3(1.7)$ & $2(3.7)$ & $7.00(0.57-85.38)$ & 0.127 \\
\hline Burning Sensation \& Irritation only & $11(6.3)$ & $7(13.0)$ & $6.13(1.49-25.22)$ & $0.012^{*}$ \\
\hline Burning Sensation only & $4(2.3)$ & $1(1.9)$ & $1.17(0.11-12.48)$ & 0.899 \\
\hline Discharge only & $59(33.5)$ & $18(33.3)$ & $1.54(0.63-3.76)$ & 0.347 \\
\hline Irritation \& Discharge only & $37(21.0)$ & $13(24.1)$ & $1.90(0.72-5.02)$ & 0.198 \\
\hline Irritation only & $9(5.1)$ & $2(3.7)$ & $1.02(0.18-5.59)$ & 0.988 \\
\hline No symptom & $45(25.6)$ & $10(18.5)$ & 1 & \\
\hline Total & $176(100.0)$ & $54(100.0)$ & & \\
\hline
\end{tabular}

\section{$\mathrm{X}^{2}=0.143$}

Data is presented as frequency and percentage in parenthesis

Positive represents pregnant women who were culture positive for VVC

$\mathrm{X}^{2}$ is the $p$-value obtained with the chi-square test

Table 5 Association between socio-demographic characteristics and vulvovaginal candidiasis ( $N=176)$

\begin{tabular}{llllll}
\hline WC & & OR & $P-$ & AOR \\
(Adjusted) & $P-$ \\
value \\
Positive & Negative & & (Unadjusted) & value & for \\
$n(\%)$ & $n(\%)$ & & OR & AOR
\end{tabular}

Total respondents $\quad 54(30.7) \quad 122(69.3)$

\section{Age group (in years)}

$\begin{array}{lllll}<20 & 6(11.1) & 6(4.9) & 1.0 & - \\ 20-29 & 24(44.4) & 61(50.0) & 0.67(0.20-2.23) & 0.514 \\ 30-39 & 22(40.7) & 52(42.6) & 0.88(0.24-3.19) & 0.848 \\ 40-49 & 2(3.7) & 3(2.5) & 0.88(0.62-12.45) & 0.925\end{array}$

\section{Educational Status}

$\begin{array}{lllll}\text { None } & 1(1.9) & 5(4.1) & 1.0 & - \\ \text { Basic } & 29(53.7) & 62(50.8) & 0.77(0.07-9.15) & 0.837 \\ \text { Secondary } & 12(22.2) & 23(18.9) & 0.80(0.06-10.29) & 0.867 \\ \text { Tertiary } & 12(22.2) & 32(26.2) & 0.62(0.05-7.76) & 0.711\end{array}$

\section{Marital Status}

$\begin{array}{lllll}\text { Single } & 12(22.2) & 21(17.2) & 1.0 & - \\ \text { Co-habitation } & 6(11.1) & 7(5.7) & 0.73(0.31-1.72) & 0.469 \\ \text { Married } & 36(66.7) & 94(77.0) & 1.47(0.38-5.62) & 0.575\end{array}$

\section{Religion}

$\begin{array}{llll}\text { Muslim } & 0(0.0) & 6(4.9) & 1.0 \\ \text { Christian } & 54(100.0) & 116(95.1) & 0.0\end{array}$

Trimester in pregnancy

$\begin{array}{lllll}\text { First } & 9(16.7) & 19(15.6) & 1.0 & - \\ \text { Second } & 14(25.9) & 29(23.8) & 0.98(0.34-2.81) & 0.963 \\ \text { Third } & 31(57.4) & 74(60.7) & 0.86(0.34-2.19) & 0.755\end{array}$


Table 6 Prevalence of symptoms of WC in relation to trimester of pregnancy

\begin{tabular}{|c|c|c|c|c|}
\hline Symptoms & 1st trimester & 2nd trimester & 3rd trimester & Total \\
\hline All Symptoms & $1(3.6)$ & $3(7.0)$ & $4(3.8)$ & $8(4.5)$ \\
\hline Burning Sensation \& Discharge only & $1(3.6)$ & $1(2.3)$ & $1(1.0)$ & $3(1.7)$ \\
\hline Burning Sensation \& Irritation only & $1(3.6)$ & $3(7.0)$ & $7(6.7)$ & $11(6.3)$ \\
\hline Burning Sensation only & $1(3.6)$ & 0 & $3(2.9)$ & $4(2.3)$ \\
\hline Discharge only & $8(28.6)$ & $15(34.9)$ & $36(34.3)$ & $59(33.5)$ \\
\hline Irritation \& Discharge only & $7(25.0)$ & $8(18.6)$ & $22(21.0)$ & $37(21.0)$ \\
\hline Irritation only & $1(3.6)$ & $2(4.7)$ & $6(5.7)$ & $9(5.1)$ \\
\hline No symptom & $8(28.6)$ & $11(25.6)$ & $26(24.8)$ & $45(25.6)$ \\
\hline Total & $28(100.0)$ & $43(100.0)$ & 105 (100.0) & $176(100.0)$ \\
\hline
\end{tabular}

$\mathrm{X}^{2}=0.992$

Data is presented as frequency and percentage in parenthesis

$\mathrm{X}^{2}$ is the $p$-value obtained with the chi-square test

the VVC-confirmed participants in our study were married. This was in contradiction to what Bitew and Abebaw [26] reported; the majority of their VVC study participants were divorced or unmarried.

Clinical presentations reported by study subjects included burning sensation around the vulva, irritation/ itching of the vulva and creamy/whitish/yellowish vaginal discharge. Although most of the study participants (35.5\%) had vaginal discharge, it had no statistical association with VVC $(P=0.143 ; P>0.05)$. Most participants had one or more of the three clinical presentations, but laboratory outcomes did not confirm them as having VVC. This outcome simply explains that clinical presentations of VVC are not pathognomonic due to the fact that other vaginal conditions may establish such presentations [2, 37]. It is therefore imperative to couple clinical presentations with laboratory outcomes in the diagnosis of VVC in pregnant women [2].

Of the 176 subjects recruited in this study, 54 were confirmed to have VVC, resulting in a prevalence rate of $30.7 \%$ among the participants. The prevalence rates we found are slightly higher than those reported by previous studies $[13,16,17,19]$. However, our data were more or less consistent with the frequencies reported by previous studies conducted in India (36\%), Uganda (45.4\%), and in the middle belt of Ghana (36.5\%) $[15,38,39]$. Notably, the highest frequency of VVC in our study was recorded in pregnant women in their third trimester (57.4\%). A similar observation was also reported in a study conducted by Babić et al. [40]. This is because during pregnancy, mostly in the third trimester, the high levels of oestrogen result in higher glycogen deposits in the vagina, and this provides a good source of carbon, which supports the proliferation of Candida spp. Moreover, oestrogen increases the affinity of Candida to the yeast cytosol receptor in vaginal epithelial cells [40].

It is reported that about $70-85 \%$ pregnant mothers with VVC subpartally contaminate their infants with Candida species [41]. During chidbirth, there could be subpartal transmission of Candida spp. from the vagina of the mother to the neonate. This may lead to generalised fungal infection in babies, especially premature

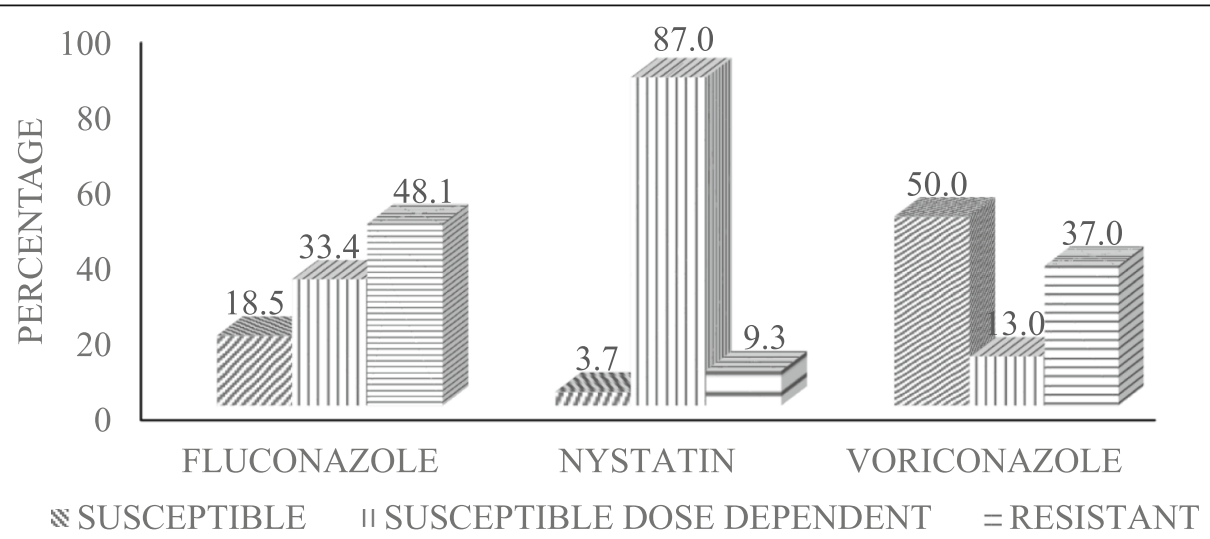

Fig. 7 A graph showing the general In vitro antifungal susceptibility pattern of Candida isolates to Fluconazole (25 $\mu \mathrm{g})$, Nystatin (100 units) and Voriconazole $(1 \mu \mathrm{g})(n=54)$ 
Table 7 In vitro Susceptibility patterns of C. albicans and non-albicans Candida species to Fluconazole (25 $\mu \mathrm{g})$, Nystatin (100 units) and Voriconazole $(1 \mu \mathrm{g})(n=54)$

\begin{tabular}{|c|c|c|c|c|c|}
\hline DRUGS & CANDIDA SPECIES & $\begin{array}{l}\text { S } \\
\text { n (\%) }\end{array}$ & $\begin{array}{l}\text { S-DD } \\
\text { n (\%) }\end{array}$ & $\begin{array}{l}\text { R } \\
\text { n (\%) }\end{array}$ & Total (\%) \\
\hline \multirow[t]{5}{*}{ FLUCONAZOLE } & C. albicans & $3(21.4)$ & $4(28.6)$ & $7(50.0)$ & $14(100.0)$ \\
\hline & Non-albicans Candida & $7(17.5)$ & $14(35.0)$ & $19(47.5)$ & $40(100.0)$ \\
\hline & C. glabrata & $6(19.4)$ & $13(41.9)$ & $12(38.7)$ & $31(100.0)$ \\
\hline & C. krusei & $0(0.0)$ & $0(0.0)$ & $6(100.0)$ & $6(100.0)$ \\
\hline & C. parapsilosis & $1(33.3)$ & $1(33.3)$ & $1(33.3)$ & $3(100.0)$ \\
\hline \multirow[t]{5}{*}{ NYSTATIN } & C. albicans & $0(0.0)$ & $14(100.0)$ & $0(0.0)$ & $14(100.0)$ \\
\hline & Non-albicans Candida & $2(5.0)$ & $33(82.5)$ & $5(12.5)$ & $40(100.0)$ \\
\hline & C. glabrata & $0(0.0)$ & $27(87.1)$ & $4(12.9)$ & $31(100.0)$ \\
\hline & C. krusei & $0(0.0)$ & $5(83.3)$ & $1(16.7)$ & $6(100.0)$ \\
\hline & C. parapsilosis & $2(66.7)$ & $1(33.3)$ & $0(0.0)$ & $3(100.0)$ \\
\hline \multirow[t]{5}{*}{ VORICONAZOLE } & C. albicans & $6(42.9)$ & $1(7.1)$ & $7(50.0)$ & $14(100.0)$ \\
\hline & Non-albicans Candida & $21(52.5)$ & $6(15.0)$ & $13(32.5)$ & $40(100.0)$ \\
\hline & C. glabrata & $17(54.8)$ & $3(9.7)$ & $11(35.5)$ & $31(100.0)$ \\
\hline & C. krusei & $2(33.3)$ & $3(50.0)$ & $1(16.7)$ & $6(100.0)$ \\
\hline & C. parapsilosis & $2(66.7)$ & $0(0.0)$ & $1(.3)$ & $3(100.0)$ \\
\hline
\end{tabular}

Data is presented as frequency and percentage in parenthesis

$S$ Susceptible

SDD Susceptible Dose Dependent

$R$ Resistant

neonates, due to their immature immunity [41]. Therefore, pregnant women with VVC in their first and second trimesters have a high chance of having Candida chorioamnionitis, which may cause abortion [42]. VVC may also lead to low birth weights and preterm babies $[43,44]$. In addition, participants with VVC may stand a risk of developing nipple candidiasis during breastfeeding when their babies develop oral thrush [45]. It is therefore imperative to offer prepartal treatment to pregnant women diagnosed with VVC [41].

We found that HiCrome Candida differential agar is efficient for routine identification of Candida isolates in the clinical setting. Our study showed that the HiCrome is effective for identification of four medically important Candida isolates to the species level (Table 1). It has more advantage than the germ tube test, which could only categorise isolates as germ tube positive or negative $[27,29]$. The only advantage the germ tube test had over HiCrome in our study was with the turn around time of $4 \mathrm{~h}$ as against $48 \mathrm{~h}$ for HiCrome [27, 28, 30].

Of the two broad species of Candida isolated, 74.1\% were NAC whilst $25.9 \%$ were C. albicans. Our observation is similar to those of Okungbowa et al. [46] and Deorukhkar et al. [47], who found that more than 50\% of urinary Candida isolates belonged to non-albicans Candida. In the present study, C. glabrata (57.4\%), was the most frequently isolated species followed by $C$. albicans (25.9\%), C. krusei (11.1\%) and C. parapsilosis (5.6\%). As in our study, the predominance of C. glabrata over C. albicans has been reported in Nigeria and India $[46,48]$. However, our result differs from other studies that implicate $C$. albicans as the predominant Candida species among pregnant women causing VVC [13, 17, 35]. Further, our results close to those of other studies reporting C. glabrata as the second most predominate Candida species [13, 35, 49]. From these studies, the presence of C. glabrata as the second most predominant Candida isolate could explain the gradual increased shift of $C$. albicans to C. glabrata in causing VVC. The predominance of C. glabrata in VVC in our study could be as a result of self-medication and prolonged antifungal therapy, which may have led to the selection of C. glabrata over $C$. albicans, due to their increased resistance to the commonly used antifungal agents that can be purchased over the counter [2,33].

The current findings showed that $48.1 \%$ of Candida isolates were resistant to fluconazole by disc diffusion method. A similar resistance pattern was reported in studies from India (19.44\%) [35] and from Nigeria (24, 36.2\%) [17, 50].

The high resistance pattern of Candida isolates to fluconazole in our study may be due to the use of fluconazole mainly for empiric treatment of VVC [20]. As compared to nystatin and voriconazole, all 6 C. krusei isolates studied were resistant to fluconazole. This is similar to previous reports that Candida krusei is intrinsically resistant to fluconazole [51].

Our study showed that $3.7 \%$ isolates were susceptible to nystatin, while $9.3 \%$ were resistant with high SDD 
values. On the contrary, some studies reported that Candida species showed no resistance to nystatin, with low SDD values [51-53]. Although fluconazole has been used as the first-line empiric antimycotic drug over the years, its efficacy was very low in the current study very low indicating that there has been a shift of usage from fluconazole to nystatin (Fig. 7). In our study, nystatin was recorded as having the lowest resistance pattern compared to fluconazole and voriconazole. Previous reports suggested that yeasts are universally susceptible to nystatin [54]. However, the low percentage of susceptibility to nystatin in our study can also be attributed to a lack of routine susceptibility testing of nystatin and other antifungal agents.

In this study, all the tested species showed a high susceptibility to voriconazole as compared to fluconazole. C. krusei $(33.3 \%)$ which were resistant to fluconazole, showed high susceptibility to voriconazole. Moreover, a higher frequency of resistance to voriconazole was seen in C. albicans than in non-albicans Candida, but the difference was not statistically significant. A similar susceptibility pattern was also observed in other studies carried out in India, Turin and Italy [55], and the results of these studies validate the idea that voriconazole could be a promising antifungal agent against active infections caused by Candida spp. innately resistant to fluconazole.

\section{Limitations}

Our study has some limitations. First, a limited number of participants were enrolled during the study period due to time constraints. Second, other antifungal disks were not readily available, resulting in the use of only three for this study. Last, due to small groups of participants and information not being readily available in the ANC books, we could not get significant data on patients' personal hygiene, and could not identify whether the patients were multipara or nullipara.

\section{Conclusion}

Our findings showed high prevalence of VVC among the pregnant women in the study area. We also found $C$. glabrata to be the predominant isolates causing VVC among the pregnant women, followed by $C$. albicans. Most Candida isolates in our study were susceptible to voriconazole, which favours its use in empiric treatment considering its broad spectra [56]. However, nystatin recorded the lowest resistance pattern compared to fluconazole and voriconazole. Variations in degrees of susceptibility, SDD and resistance patterns among the three antifungal agents make species identification and antifungal susceptibility testing in routine diagnosis imperative for selection of appropriate antifungal therapy in Ghana. This will prevent treatment failure, thereby avoiding recurring VVC and persistence of resistant strains which can be passed on subpartally to neonates. HiCrome Candida differential agar has high efficacy in speciation of Candida isolates and should be used in combination with the germ tube test in identification of Candida isolates. The outcome of germ tube test, which is rapid, could be given as a preliminary report while awaiting the outcome of HiCrome, which takes about $48 \mathrm{~h}$.

\section{Abbreviations}

ANC: Antenatal Clinic; BHI: Brain Heart Infusion; C: Candida; CLSI:: Clinical and Laboratory Standard Institute; HMH:: Ho Municipal Hospital; HTH: Ho Teaching Hospital; HVS:: High Vaginal Swab; MH:: Mueller Hinton; mm:: Millimeters; OTC:: Over The Counter; PID:: Pelvic Inflammatory Disease; SDA:: Sabouraud Dextrose Agar; SDD:: Susceptible-Dose Dependent; Spp:: Species; SPSS:: Statistical Package for the Social Sciences; $\mu \mathrm{g}:$ : Microgram

\section{Acknowledgements}

We dedicate this paper to the late Mr. Benedict Kwame Awadzi who was supposed to be the author but sadly, passed away after a fatal lorry accident before the publication of our manuscript.

The authors are grateful to Lydia Akotia and Abdullahi Ahmed Tijani of HTH for providing technical support. We are also thankful to management and staff of the Microbiology Laboratory $(\mathrm{HTH})$ and Antenatal clinic, Ho Teaching Hospital and Ho Municipal Hospital. Our sincere appreciation go to our consented study participants for their cooperation.

\section{Consent to publication}

Not applicable.

\section{Authors' contributions}

IA, SDW, GSK and BL conceived and designed the study; GSK, IA, HKM, PM, CYA collected, processed samples and collected data; IA, SDW and HKM supervised the study; GYO, JGD, CD, JT, JK produced the first draft manuscript; SDW, GYO, GSK, EAA, JAO and ESK analyzed data; all authors critically reviewed the manuscript and made significant input; all authors read and approved the final manuscript.

Funding

No specific funding obtained.

\section{Availability of data and materials}

The dataset generated during and/or analyzed for this current study are not publicly available. However, coded data may be available from the corresponding author on reasonable request.

\section{Ethics approval and consent to participate}

Ethical approval of the study was granted by the University of Health and Allied Sciences Research Ethics Committee (UHAS-REC), with Protocol Identification Number, UHAS-REC/A.5(49)17-18. Written informed consent was obtained from all participants before enrollment into study after the objectives and procedures of the study were explained in details. For participants below the age of 18 years, written informed consent was obtained from their parents. The identity and records of participants were codified prior to analysis. Each participant was given the right to refuse to take part in the study and to withdraw at any time during the study period. Results were made available to the antenatal unit for the proper management of the consented participants.

\section{Competing interests}

The authors declare that they have no competing interests.

\section{Author details}

'Department of Biomedical Sciences, School of Basic and Biomedical Sciences, University of Health and Allied Sciences, PMB 31 Ho, Ghana. ${ }^{2}$ Department of Medical Laboratory Sciences, School of Allied Health Sciences, University of Health and Allied Sciences, Ho, Ghana. ${ }^{3}$ Gynecology Department, Ho Teaching Hospital, Ho, Ghana. ${ }^{4}$ Public Health Department, 
Ho Teaching Hospital, Ho, Ghana. ${ }^{5}$ Department of Biostatistics and Epidemiology, School of Public Health, University of Health and Allied Sciences, Ho, Ghana. ${ }^{6}$ Medical Laboratory Department, Ho Teaching Hospital, Ho, Ghana. ${ }^{7}$ Department of Pharmaceutical Microbiology, School of Pharmacy, University of Health and Allied Sciences, Ho, Ghana. ${ }^{8}$ Urology Department, Ho Teaching Hospital, Ho, Ghana. ${ }^{9}$ Pharmacy Department, Ho Teaching Hospital, Ho, Ghana. ${ }^{10}$ Microbiology Department, University of Ghana Medical School, Accra, Ghana.

\section{Received: 22 October 2019 Accepted: 21 April 2020}

\section{Published online: 06 May 2020}

\section{References}

1. Sobel J. Vaginal infections in adult women. Med Clin N Am. 1990;74(6): 1573-602.

2. Sobel JD, Faro S, Force RW, Foxman B, Ledger WJ, Nyirjesy PR, et al. Vulvovaginal candidiasis: epidemiologic, diagnostic, and therapeutic considerations. Am J Obstet Gynecol. 1998;178(2):203-11.

3. Sobel JD. Vulvovaginal candidosis. Lancet. 2007;369(9577):1961-71.

4. Ahmad A, Khan AU. Prevalence of Candida species and potential risk factors for vulvovaginal candidiasis in Aligarh, India. Eur J Obstet Gynecol Reprod Biol. 2009;144(1):68-71.

5. Fidel P. Host defense against oropharyngeal and vaginal candidiasis: sitespecific differences. Rev Iberoam Micol. 1999;16:8-15.

6. Nohmi T, Abe S, Dobashi K, Tansho S, Yamaguchi H. Suppression of antiCandida activity of murine neutrophils by progesterone in vitro: a possible mechanism in pregnant women's vulnerability to vaginal candidiasis. Microbiol Immunol. 1995;39(6):405-9.

7. Bauters TG, Dhont MA, Temmerman MI, Nelis HJ. Prevalence of vulvovaginal candidiasis and susceptibility to fluconazole in women. Am J Obstet Gynecol. 2002;187(3):569-74.

8. Nelson M, Wanjiru W, Margaret MW. Prevalence of vaginal candidiasis and determination of the occurrence of Candida species in pregnant women attending the antenatal clinic of Thika District hospital. Kenya Open Journal of Medical Microbiology. 2013;3(4):264.

9. Fidel PL, Cutright J, Steele C. Effects of reproductive hormones on experimental vaginal candidiasis. Infect Immun. 2000;68(2):651-7.

10. Ellepola A, Samaranayake $L$. The effect of limited exposure to antimycotics on the relative cell-surface hydrophobicity and the adhesion of oral Candida albicans to buccal epithelial cells. Arch Oral Biol. 1998;43(11):87987.

11. Dan M, Poch F, Levin D. High rate of vaginal infections caused by non-C. albicans Candida species among asymptomatic women. Med Mycol. 2002; 40(4):383-6

12. Oviasogie F, Okungbowa F. Candida species amongst pregnant women in Benin city, Nigeria: effect of predisposing factors. Afr J Clin Exp Microbiol. 2009;10(2):92-8.

13. Abruquah $\mathrm{H}$. Prevalence and antifungal susceptibility of Candida species isolated from women attending a gynaecological clinic in Kumasi, Ghana. J Sci Technology (Ghana). 2012;32(2):39-45.

14. Feglo P, Narkwa P. Prevalence and antifungal susceptibility patterns of yeast isolates at the Komfo Anokye teaching hospital (KATH), Kumasi, Ghana; 2012.

15. Sasikala G, Agatha D, Janagond BA, Thenmozhivalli PR. Characterization of Candida and its antifungal susceptibility pattern from patients with vaginal candidiasis in a Tertiiary care hospital in South India. J Pharmaceutical Biomed Sci. 2013;30(30):51-6.

16. Al-akeel RA, El-kersh TA, Al-Sheikh YA, Al-Ahmadey ZZ. Prevalence and comparison for detection methods of Candida species in vaginal specimens from pregnant and non pregnant Saudi women. Afr J Microbiol Res. 2013; 7(1):56-65.

17. James GD, Essieen UC, Victoria MD. Prevalence and antifungal susceptibility profile of Vulvovaginal candidiasis amongst women of reproductive age in Jos Metropolis, Nigeria. World J Pharmaceutical Life Sci. 2017:3(3):152-6.

18. Pirotta MV, Garland SM. Genital Candida species detected in samples from women in Melbourne, Australia, before and after treatment with antibiotics. J Clin Microbiol. 2006:44(9):3213-7.

19. Oyeyipo 00 , Onasoga MF. Incidence and speciation of Candida species among non-gravid young females in Ilorin, north central, Nigeria. J Appl Sci Environ Manag. 2015;19(4):680-5.
20. Pam VK, Akpan JU, Oduyebo OO, Nwaokorie FO, Fowora MA, Oladele RO, et al. Fluconazole susceptibility and ERG11 gene expression in vaginal Candida species isolated from Lagos Nigeria. Int J Mol Epidemio Genet. 2012;3(1):84.

21. Meizoso T, Rivera T, Fernández-Aceñero M, Mestre M, Garrido M, Garaulet $C$. Intrauterine candidiasis: report of four cases. Arch Gynecol Obstet. 2008; 278(2):173-6.

22. Liguori G, Di Onofrio V, Lucariello A, Gallé F, Signoriello G, Colella G, et al. Oral candidiasis: a comparison between conventional methods and multiplex polymerase chain reaction for species identification. Oral Microbiol Immunol. 2009;24(1):76-8.

23. Baradkar V, Mathur M, Kumar S. Hichrom candida agar for identification of Candida species. Indian J Pathol Microbiol. 2010;53(1):93.

24. Vijaya D, Dhanalakshmi TA, Kulkarni S. Changing trends of vulvovaginal candidiasis. J Laboratory Phys. 2014;6(1):28.

25. Esmaeilzadeh S, Omran SM, Rahmani Z. Frequency and etiology of vulvovaginal candidiasis in women referred to a gynecological center in babol, Iran. Int J Fertil Steril. 2009;3:2.

26. Bitew A, Abebaw Y. Vulvovaginal candidiasis: species distribution of Candida and their antifungal susceptibility pattern. BMC Womens Health. 2018;18(1): 94.

27. Howell SA, Hazen KC. Candida, Cryptococcus, and other yeasts of medical importance. Manual of Clinical Microbiology, 10th Edition: American Society of Microbiology; 2011. p. 1793-821.

28. Sangaré I, Sirima C, Bamba S, Zida A, Cissé M, Bazié W, et al. Prevalence of vulvovaginal candidiasis in pregnancy at three health centers in Burkina Faso. Journal de mycologie medicale. 2018;28(1):186-92.

29. Shettar SK, Patil AB, Nadagir SD, Shepur T, Mythri B, Gadadavar S. Evaluation of HiCrome differential agar for speciation of candida. J Acad Med Sci. 2012; 2(3):101.

30. HiMedia. HiCrome ${ }^{\mathrm{TM}}$ Candida Differential Agar. HiMedia Laboratories. 2018.

31. Rati R, Patel J, Rishi S. Vulvovaginal Candidiasis and its Antifungal Susceptibility Pattern: Single center experience. International Journal of Medical Research and Review 2015;3(1).

32. Diagnostica R. Suceptibility testing of yeasts 2011. Taastrup: Rosco Diagnostica; 2011.

33. Spinillo A, Nicola S, Colonna L, Marangoni E, Cavanna C, Michelone G. Frequency and significance of drug resistance in vulvovaginal candidiasis. Gynecol Obstet Investig. 1994;38(2):130-3.

34. Amar C, Ashish J, Hajare V, Belagali Y. Study of prevalence and antifungal susceptibility of candida. Int J Pharm Bio Sci. 2013;4(2):361-81.

35. Sasikala G, Agatha D, Janagond A, Thenmozhivalli P. Characterization of Candida and its antifungal susceptibility pattern from patients with vaginal candidiasis in a tertiary care hospital in South India. J Pharmaceutical Biomedical Sci May (Supplement 1). 2013;30(30):S1-6.

36. Rati R, Patel J, Rishi S. Vulvovaginal Candidiasis and its Antifungal Susceptibility Pattern: Single center experience. Int J Med Res Rev. 2015;3:1.

37. Schaaf VM, Perez-Stable EJ, Borchardt K. The limited value of symptoms and signs in the diagnosis of vaginal infections. Arch Intern Med. 1990;150(9): 1929-33.

38. Mukasa KJ, Herbert I, Daniel A, Sserunkuma KL, Joel B, Frederick B. Antifungal susceptibility patterns of vulvovaginal Candida species among women attending antenatal clinic at Mbarara regional referral hospital, South Western Uganda. Brit Microbiol Res J. 2015;5(4):322.

39. Konadu DG, Owusu-Ofori A, Yidana Z, Boadu F, Iddrisu LF, Adu-Gyasi D, et al. Prevalence of vulvovaginal candidiasis, bacterial vaginosis and trichomoniasis in pregnant women attending antenatal clinic in the middle belt of Ghana. BMC Pregnancy Childbirth. 2019;19(1):341.

40. Babić M, Hukić M. Candida albicans and non-albicans species as etiological agent of vaginitis in pregnant and nonpregnant women. Bosnian J Basic Med Sci. 2010;10(1):89.

41. Blaschke-Hellmessen R. Subpartale Übertragung von Candida und ihre Konsequenzen: Subpartal transmission of Candida and its consequences. Mycoses. 1998:41:31-6.

42. Donders G, Moerman P, Caudron J, Van Assche FA. Intra-uterine Candida infection: a report of four infected fetusses from two mothers. Eur J Obstetrics Gynecology Reprod Biology. 1991;38(3):233-8.

43. Leli C, Mencacci A, Meucci M, Bietolini C, Vitali M, Farinelli S, et al. Association of pregnancy and Candida vaginal colonization in women with or without symptoms of vulvovaginitis. Minerva Ginecol. 2013; 65(3):303-9. 
44. Holzer I, Farr A, Kiss H, Hagmann M, Petricevic L. The colonization with Candida species is more harmful in the second trimester of pregnancy. Arch Gynecol Obstet. 2017;295(4):891-5.

45. Tanguay KE, McBean MR, Jain E. Nipple candidiasis among breastfeeding mothers. Case-control study of predisposing factors. Can Family Physician. 1994:40:1407.

46. Okungbowa FI, Isikhuemen O, Dede AP. The distribution frequency of Candida species in the genitourinary tract among symptomatic individuals in Nigerian cities. Rev Iberoam Micol. 2003;20(2):60-3.

47. Deorukhkar SC, Saini S, Mathew S. Non-ablicans Candida infection: an emerging threat. Interdisciplinary Perspectives on Infectious Diseases. 2014; 2014:7.

48. Mohanty S, Xess I, Hasan F, Kapil A, Mittal S, Tolosa JE. Prevalence \& susceptibility to fluconazole of Candida species causing vulvovaginitis. Indian J Med Res. 2007:126(3):216.

49. Mnge P, Okeleye B, Vasaikar S, Apalata T. Species distribution and antifungal susceptibility patterns of Candida isolates from a public tertiary teaching hospital in the Eastern Cape Province, South Africa. Brazilian J Med Biological Res. 2017;50:6.

50. Osaigbovo II, Lofor PV, Oladele RO. Fluconazole resistance among oral Candida isolates from people living with HIV/AIDS in a Nigeria tertiary hospital. J Fungi (Basel). 2017;3(4):69.

51. Sajjan AC, Mahalakshmi V, Hajare D. Prevalence and antifungal susceptibility of Candida species isolated from patients attending tertiary care hospital. J Dental Med Sci. 2014;13(5):44-9.

52. Liu $X$, Fan S, Peng $Y$, Zhang $H$. Species distribution and susceptibility of Candida isolates from patient with vulvovaginal candidiasis in southern China from 2003 to 2012. Journal de mycologie medicale. 2014;24(2):10611.

53. Fan S, Liu X. In vitro fluconazole and nystatin susceptibility and clinical outcome in complicated vulvovaginal candidosis. Mycoses. 2011;54(6):5015 .

54. Dick J, Merz W, Saral R. Incidence of polyene-resistant yeasts recovered from clinical specimens. Antimicrob Agents Chemother. 1980;18(1):158-63.

55. Mandras N, Tullio V, Allizond V, Scalas D, Banche G, Roana J, Robbiano F, Fucale G, Malabaila A, Cuffini AM, Carlone N. In vitro activities of fluconazole and voricanazole against clinical isolates of Candida spp. determined by disk diffusion testing in Turin, Italy. Antimicrob Agents Chemother. 2009; 53(4):1657-9.

56. Török E, Moran E, Cooke F. Oxford handbook of infectious diseases and microbiology: Oxford University press; 2016.

\section{Publisher's Note}

Springer Nature remains neutral with regard to jurisdictional claims in published maps and institutional affiliations.

Ready to submit your research? Choose BMC and benefit from:

- fast, convenient online submission

- thorough peer review by experienced researchers in your field

- rapid publication on acceptance

- support for research data, including large and complex data types

- gold Open Access which fosters wider collaboration and increased citations

- maximum visibility for your research: over $100 \mathrm{M}$ website views per year

At $\mathrm{BMC}$, research is always in progress.

Learn more biomedcentral.com/submissions 